\title{
A Case Study on Integrating a Facebook Group Into a Computer Programming Course
}

\author{
Hasan Tinmaz, Woosong University, South Korea
}

Jin Hwa Lee, Woosong University, South Korea

\begin{abstract}
The researchers conducted a study in a computer programming course of three engineering departments (civil, industrial, and mechatronics) in a Turkish private university $(\mathrm{n}=240)$. A closed Facebook group was set up for serving as an LMS for the course. At the end of the semester, the students were given a survey of three sections: demographic questions, three opinion-based questions on Facebook group use, and 32 Facebook-in-education perception-related 5-Likert scale. The mean scores showed that the majority of the students liked using a closed Facebook group. The two most important reasons were accessing the shared lecture notes ubiquitously and keeping themselves updated on anything related to the course. Additionally, the students agreed on the idea of keeping the Facebook group secret and the importance of establishing group rules. The students also reported that the Facebook group was not a waste of time or uninteresting for them. Lastly, comparison tests showed that there were certain items yielding significant differences based on gender, school year, and department variables.
\end{abstract}

\section{KEYWORDS}

Communication in Classroom, Computer Programming, Facebook, Facebook Group, Freedom of Students, Student Perception

\section{INTRODUCTION}

Social media platforms have evolved in many different ways over the years and their influences in our daily lives have expanded dramatically. It becomes more visible that we cannot keep people away from these social media platforms, especially the youth. In that sense, different scholars and stakeholders have initiated different attempts to integrate these platforms into different practices of daily lives. Education has been one of these practices as a result of wide expansion of youth's mobile device accessibility and their unstoppable registrations to these social media platforms.

As one of the most popular social media platforms, Facebook has served the purpose of being entertainment and social networking tools. However, the utilization of Facebook is not only limited to being a social media platform for gratification. With ongoing implementations of Information and Communication Technologies (ICT) in education, Facebook has been considered and experimented for educational usage. Through various studies, benefits and drawbacks of Facebook usage in education were reported along with pedagogical mechanisms involved. It is undeniably important to experiment and measure the outcomes of Facebook usage through class assessment or examination 
results, however, one must also consider how students' learning behaviors or thinking processes are influenced.

As such, it is necessary to assess students' perceptions towards the Facebook implementation in learning as well as identify possible factors that can affect students' perceptions. A deeper understanding of the underlying mechanisms for students' perceptions will give us a correct guideline for Facebook implementations in learning and eventually broaden the spectrum of educational tools. Therefore, this study focuses on a case where the different engineering students were utilized a closed Facebook group as their learning management tool throughout the semester within their computer programming course.

\section{LITERATURE REVIEW}

Among various social media platforms, Facebook is one of the most popular platforms and its use for educational purpose has been studied extensively. One of the benefits of using Facebook in education is that it encourages interactions among students and between students and the instructors. Arteaga Sánchez, Cortijo, and Javed (2014) conducted a survey on 214 undergraduate students in Spain to investigate their perception of using Facebook in class. Most students believed that Facebook can create more opportunities for communication and collaboration with other students.

Facebook has been also reported to increase academic performance in Further Education and Training (FET) colleges in South Africa (Dzvapatsva, Mitrovic, \& Dietrich, 2014). One of the biggest challenges in Information Technology (IT) lectures was the lack of adequate contact hours for the course which negatively affected students' academic performance. However, Dzvapatsva, Mitrovic, and Dietrich (2014) found that students using Facebook had increased contact learning time with other students and lecturers and showed approximately 35\% improvement in academic performance.

Due to the benefits of using Facebook in class, studies have also attempted to use Facebook as an alternative for LMS. LaRue (2012) examined the potential of Facebook being the sole LMS in a nursing course. The course name was 'Internet and Health Informatics' which consisted of face-toface and online classes. Facebook was used for weekly blog posting with various topics related to the course. As the results, Facebook was reported to be an effective classroom management tool for both face-to-face and online sessions.

Similar findings were reported by Meishar-Tal, Kurtz, and Pieterse (2012). The study implemented Facebook as a course LMS for fifty college students. The course name was 'International Aspects of ICT in Education' and it was a face-to-face course with class meetings once a week over thirteen weeks. Based on students' feedback, the study reported that Facebook can provide intensive and collaborative learning environment. This is because Facebook can easily promote interaction among students and instructors. While traditional LMS is mainly used at content-based level, Facebook was perceived by students as a dynamic learning environment.

Although Facebook has a great potential for educational use, there are also a number of concerns involved with Facebook. One of the concerns is that students could initially perceive Facebook as a socializing tool rather than an academic tool. This can make certain students feel uncomfortable if they were asked to use Facebook for academic purpose. In other words, there is a need for boundary between social and academic usage of Facebook (Niu, 2019). From a study conducted by Gettman and Cortijo (2015), it was found that students generally felt reluctant to use Facebook for academic purposes. This is because students perceived Facebook as a social medium and felt uncomfortable interacting with instructors on Facebook. In particular, increased number of instructors on Facebook also promoted the level of discomfort students felt (Gettman \& Cortijo, 2015). Thus, students' perception of Facebook should be carefully considered before Facebook is implemented in teaching and learning.

Another concern with Facebook is that its effectiveness can vary depending on academic disciplines. Although many studies in language education reported in favor of Facebook, certain 
academic disciplines reported different results. Lin, Hou, Wu, and Chang (2014) conducted a study on students' learning gains in the course 'Introduction to the Network'. Students were tested on network troubleshooting skills and their learning were facilitated by Facebook discussion or by simulationbased teaching software. Through this study, it was found that simulation-based software produced higher level of cognitive processing from the students than using Facebook. Although learning gains were evident in both learning facilitators, it is clear that there is a better alternative to Facebook in certain academic disciplines.

As mentioned earlier, benefits and drawbacks of using Facebook have been studied in many academic disciplines in order to implement it in the most effective way. In particular, Facebook is getting attention in computer education. This is due to the fact that students of beginner levels often experience difficulties in learning computer programming and there is a need for implementing various educational tools (Aşkar \& Davenport, 2009; Pillay \& Jugoo, 2005). Indeed, Öztürk and Akgün (2012) emphasized the necessity of incorporating social media platforms, such as Facebook, into university courses.

To assess the effectiveness of Facebook in programming learning, a study was conducted on sixty three freshman students and eight faculty members of a university in Turkey (Özyurt \& Özyurt, 2016). The course title was 'Introduction to Programming and Algorithm' offered by the software engineering department. This study reported that Facebook was effective in providing a rich content in programming learning, increasing extracurricular communication and motivation, creating cooperative learning environment, and bringing different perspectives. However, minor drawbacks of using Facebook were causing distractions, decreasing face-to-face communication, and experiencing problems in expressing oneself.

As mentioned above, Facebook can create collaborative learning environment and has a great potential to replace the traditional LMS. With minor drawbacks, Facebook usage was also reported to be effective for computer education courses. However, there are still ongoing discussions about the implementation of Facebook under the educational settings. While previous studies have reported various results regarding Facebook implementations, how students perceive Facebook usage in their class has not been clarified. As students' perception can influence their acceptance level for Facebook, it is one of the key factors that determine the success of Facebook implementation.

Thus, our study aims to further investigate students' perceptions on Facebook usage and also perform comparative analyses on various factors in relation to students' perceptions. These factors considered for our study were students' gender, academic year level, and department. This was due to their significance in Facebook usage as reported in previous studies (Garcia et al., 2018; Jung, 2018; Lin et al., 2014; Özyurt \& Özyurt, 2016) and also their relevance to our study topic.

The outcomes of our study will become a meaningful addition to current literature as they will elucidate how students perceive Facebook in a computer programming course as well as how student-related factors influence students' perceptions towards Facebook usage. After all, it is more important to understand how students perceive and use educational tools before we discuss about the potential benefits (Kalin, 2012).

\section{METHOD}

\section{Study Sample and Context}

Since the general aim of this study is to utilize a social media platform as a learning environment in computing education, the researchers applied a purposeful sampling for this study. The researchers selected Facebook, since it is the most common and well-known social media platform for the students' learning environment. Additionally, since the students were engineering students, they would not have any technical problems to use another platform for their learning. As Fraenkel, Wallen and Hyun (2012) pointed out, purposeful sampling will work at best when the researchers want to understand a phenomenon (social media platform as a learning environment in computing education) over a 
Table 1. Participants' gender versus department cross-tabulation

\begin{tabular}{|c|c|c|c|c|}
\hline & \multicolumn{3}{|c|}{ Departments } & \\
\hline Gender & Civil Engineering & Industrial Engineering & Mechatronics Engineering & Total \\
\hline Female & 6 & 33 & 11 & $50(21 \%)$ \\
\hline Male & 65 & 62 & 63 & $190(79 \%)$ \\
\hline Total & $71(29 \%)$ & $95(40 \%)$ & $74(31 \%)$ & 240 \\
\hline
\end{tabular}

particular sample (without having any technical barrier or adverse perception toward technological innovations).

Specifically, this study was conducted in a 'Computer Programming' course of three departments (Civil Engineering, Industrial Engineering and Mechatronics Engineering) in a Faculty of Engineering and Architecture in a Turkish private university $(n=240)$. There were two separate sections for each department where students were learning about underlying concepts and principles of programming. The course emphasized the design and implementation of coding in $\mathrm{C}$ programming language with the following topics; general structure of a $\mathrm{C}$ programming, data types, variables, standard functions, subprograms, selection statements, loops, text files, user-defined data types, records, pointers and dynamic data structures.

The students were either in their sophomore $(n=116,48 \%)$ or junior $(n=124,52 \%)$ year. Table 1 summarizes gender and departmental distributions of the students. It shows majority of the students were male.

One of the authors in this article was teaching this course with two research assistants who were helping the course instructor throughout the fifteen-week long semester. The course instructor decided to utilize Facebook's group feature as a course management platform by considering previous semesters' student critics on the existing university LMS (especially on lack of active notifications within the learning management system). In order to offer a better platform, the course instructor opened another Facebook account with the given university email. Hence, the course group would look more professional to students, the separation of personal and professional accounts would be provided aiming no intervention to any private life, and any request or update would be seen as an email to the course instructor.

The course instructor initially created a Facebook group through a new Facebook account and changed its setting to "closed" to make the group more exclusive for students. Closed Facebook groups can be searched and they are visible by their names, descriptions and joint members. On the other hand, people cannot see the content of the groups unless they become a member. The membership requests must be approved by the group administrator. Therefore, at the first meeting of the course, the instructor announced the Facebook group and explained its purposes and uses throughout the semester. The students were suggested to join as soon as possible in order to follow the course. Moreover, the students were informed that they could get active participation points based on their effective contributions on course Facebook group.

The students' membership requests were checked by the course instructor with a list of registered students. Since this application was new to the students, the course instructor prepared a list of suggestions and rules and asked each student to read the document, sign and return to the course instructor. This document can be seen in Appendix A of this paper.

The major problem of this implementation was very few students' rejection toward joining Facebook or using their accounts for this courses. To overcome this problem, the course instructor explained that students could use someone else' accounts (who were not registered to the course this semester) or could register Facebook with basic information to open an account. At the end of the third week, all the students joined the closed Facebook group. 


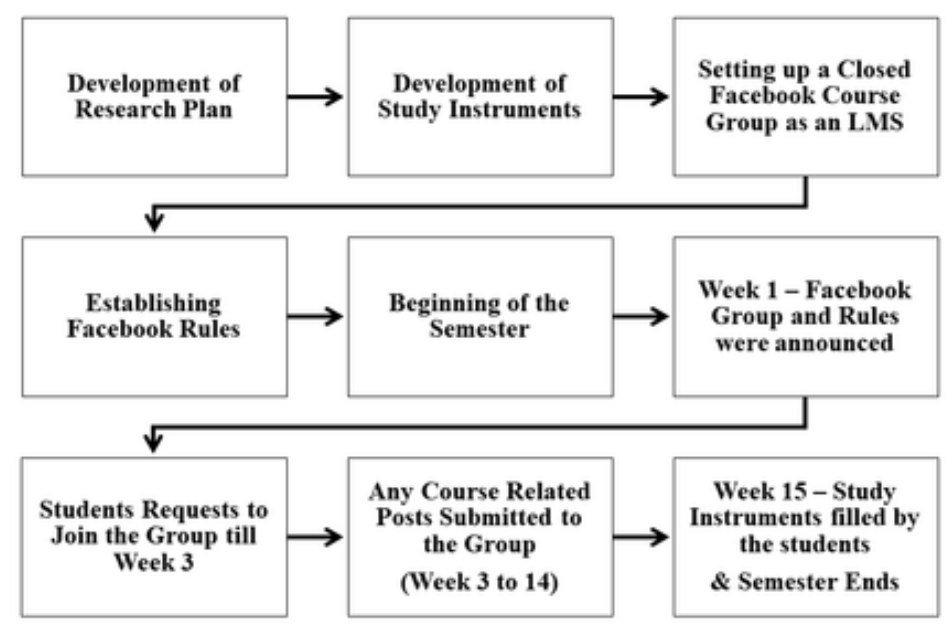

The course instructor was uploading weekly lecture notes for the group and announcing important issues (such as examination dates). Moreover, the students could message the course instructor whenever they want. Since there were many problem solving in algorithms or C coding, the students were sharing either the course instructor's writings on the board (as taking their photos and sharing on the wall) or their own solutions. The students were free to follow the course notes on their mobile phones before, during or after to lecture hours.

At the end of the semester, before the final exam, the research assistants of the course revealed the web address of the online survey and asked the students to fill the survey in the computer laboratory in thirty minutes. The course instructor waited outside to limit the possible pressure.

In a nutshell, the flow of this case study has been visualized in Figure 1.

\section{Study Instrument}

The researchers decided to develop their own study instrument addressing their research questions. Hence, they conducted a depth literature review revealing previous studies' findings and existing research instruments. As a result of that process, the researchers developed their study instrument as a survey. That survey form was checked by Turkish language expert first and given feedback from three different subject matter experts in the field. This expert-related feedback process was essential to enhance study's content validity (Bolger \& Wright, 1992).

The final version of the survey had three sections; (i) three demographic questions (gender, department, year of the study), (ii) three opinion based questions on Facebook group utilization and (iii) thirty two Facebook in education perception related 5-Likert scale (from strongly disagree to strongly agree) based questions. As Sabaitytė and Davidavičius (2017) emphasized, integration of any new technology in a group requires positive perception toward the innovative idea. Therefore, it is essential to measure students' perception toward Facebook usage as a learning environment to comprehend the outcomes of this Facebook group implementation. Finally, the last thirty two questions were checked for the reliability analysis where Cronbach alpha was calculated as 0.75 showing a satisfactory reliability for further analysis. 
Table 2. The frequencies for question 1

\begin{tabular}{|c|c|c|c|c|c|}
\hline Levels & $\mathbf{n}$ & $\%$ & Levels & $\mathbf{n}$ & $\%$ \\
\hline I did not like it at all & 6 & 2.5 & I liked it & 127 & 52.9 \\
\hline I did not like it & 0 & 0 & I liked it very much & 97 & 40.4 \\
\hline I do not have any decision & 10 & 4.2 & Total & 240 & 100.0 \\
\hline
\end{tabular}

\section{Data Analysis}

The data set initially analyzed for its demographics (gender, department and study year) and presented in a cross-tabulated form. Afterwards, three opinion based questions were analyzed for their descriptive (mean scores and standard deviations) and frequency distributions. Later that quantitative part, the same three questions were analyzed qualitatively for their open-ended sections which ask for the reasons of their marks. Students' comments were gathered under certain themes and presented in tables. Additionally, some exemplary direct quotations were provided within the text.

The thirty two questions; the third part of the survey, were checked for the reliability measure first. The result showed a satisfactory reliability $(\alpha>0.60)$ to move on for further analysis. At the beginning, all of the thirty two items were analyzed for their mean scores and standard deviations. Based on the tabulated results, the researchers made necessary comments.

In the final step of the study, three major statistical comparisons were handled among the groups of the variables on the thirty two Likert scale study items. First comparison was independent sample t-test which was based on gender variable to see whether or not gender (female versus male) makes statistical difference on these items. Two significantly differing items were tabulated and commented accordingly. Second independent sample t-test analysis was implemented on school year variable (sophomore versus junior) to unfold whether that variable makes any statistical difference on the items. One significantly differing item was presented in the table and explained accordingly.

After these independent sample t-tests, the researchers applied one way ANOVA test on department variable (civil engineering versus industrial engineering versus mechatronic engineering) to assess whether they make significant difference on study items. Five items were significantly differed around department variable. In order to find out which department(s) makes a difference, post-hoc tests were implemented. Due to the unequal number of participants in each level of the variable, Dunnett C post-hoc tests (George and Mallery, 2001) were applied and the results were reported accordingly.

\section{Results}

In the second part of the survey, the students were given three opinion based questions on Facebook group utilization. First question was about students' general idea on supporting a computing course with this Facebook group implementation. The students graded that idea from "I did not like it at all (1)" to "I like it very much(5)". The mean of this question $(n=240)$ was calculated as 4.29 with a standard deviation of 0.77 . That average shows that the students liked using a Facebook group in their C programming course. The frequency distribution of this question was tabulated below in Table 2 .

\section{Opinion Based Questions}

After marking their agreement level with question, the students were asked to write their reasons to support their marking. Ninety four percent of the students $(n=225)$ filled the box of this question. The results of this open-ended question were listed in Table 3. The two most important reasons that students liked using a Facebook group in this programming course were accessing the shared lecture notes ubiquitously and keeping themselves updated on anything related with the course. One student explained that "easy access to notes. I think that we understand better that our social media help our classes." 
Table 3. Qualitative analysis of students' answers

\begin{tabular}{|l|l|l|l|}
\hline \multicolumn{1}{|c|}{ Identified Point } & n & \multicolumn{1}{c|}{ Identified Point } & n \\
\hline Easy access to lecture notes & 123 & Follow the course deeply, other than taking notes only & 5 \\
\hline Learning course announcements/news & 65 & Getting information about exams & 4 \\
\hline Catching up with the course when absent & 24 & Sharing photos from lecture notes on the board & 4 \\
\hline Sharing problem solutions & 21 & Ability to repeat solved problems with their solutions & 4 \\
\hline Easy communication with course instructor & 20 & Being able to check previous weeks' topics & 3 \\
\hline Easy cooperation among friends & 15 & Easy sharing anything & 3 \\
\hline Following the course easily & 14 & Made course more understandable & 2 \\
\hline Easy access to examples & 12 & Bringing an order to the course & 1 \\
\hline Exchanging ideas easily & 9 & Faster flow of the lecture & 1 \\
\hline Getting ready for exams & 6 & Made me like the course & 1 \\
\hline
\end{tabular}

Due to the immediate notification feature of Facebook, the students did not miss anything important about the course. Moreover, easiness in sharing anything on the group or messaging with classmates/course instructor was listed as other important point. Interestingly enough, the students were also noted that Facebook group assisted them for getting information about exams (dates, grades and etc...) and studying for these exams. One of the students wrote that "I liked the fact that the topics covered in the course could be repeated and our instructor informed us immediately of important announcements. Even its dream is perfect."

The second opinion based question was about how free the students felt at the point of using the Facebook group in that computing course. Since the course instructor set up certain rules for managing Facebook group, the feeling freedom was another concern for this research. The students marked that question from "not free at all" to "totally free". The mean score of this question was 3.98 with 0.71 standard deviation $(n=240)$. The average shows that the vast majority of the students felt free while using Facebook group in that programming course. The frequency distribution of this question was tabulated in Table 4.

After students marked their agreement level, they were asked to write some reasons supporting their marks. Eighty seven percent of the students $(n=208)$ filled the box of this question. The results of this open-ended question was listed in Table 5. Twenty-eight percent of the students $(n=67)$ openly stated that they felt no constraints or pressure using the Facebook group. One male student pointed that "I can say that I felt comfortable in the group because the rules of the group are as they should be in our daily lives.". One female student added that "we could share even our selfie in the group".

Twenty-six students added that they were able to share anything they wanted without thinking of freedom as a concern. One male student uttered that "I knew it was temporary and I didn't know most people. So one feels a little more comfortable." Additionally, very few students noted that

Table 4. The frequencies for question 2

\begin{tabular}{|l|c|c|l|c|c|}
\hline \multicolumn{1}{|c|}{ Levels } & n & $\%$ & \multicolumn{1}{|c|}{ Levels } & n & \% \\
\hline Not free at all & 4 & 1.7 & Free & 165 & 68.8 \\
\hline Not free & 5 & 2.1 & Totally free & 41 & 17.1 \\
\hline No idea & 25 & 10.4 & Total & 240 & 100.0 \\
\hline
\end{tabular}


Table 5. Qualitative analysis of students' answers

\begin{tabular}{|l|c|l|l|}
\hline \multicolumn{1}{|c|}{ Identified Point } & n & \multicolumn{1}{|c|}{ Identified Point } & n \\
\hline Feeling no pressure/limit at all & 67 & Free to make jokes & 2 \\
\hline Shared anything with no problem & 26 & Free, unless sharing extreme points & 2 \\
\hline Groups rules were like daily social norms & 9 & Was expelled for one week because of my post & 2 \\
\hline Feeling free to make any comment & 6 & We were not technically free due to group rules & 1 \\
\hline Feeling the respect within the group & 4 & Too serious as a Facebook group & 1 \\
\hline Feeling free due to instructor on the group & 4 & Feeling equality among group & 1 \\
\hline Nothing shared deleted & 3 & Nervous about other students' reactions & 1 \\
\hline Free within moral values & 3 & & \\
\hline
\end{tabular}

Facebook groups are ought to have rules as well, which is very similar to other human groups living within certain social norms. On the other hand, some negative points were also written as answers, such as; making Facebook group very serious (against its social and funny dynamics), existence of rules destroying freedom at all, and adverse experiences on expelling from the group for a short period time. One female student reported that "Since all the students could share anything without taking permission [...no moderation...] increased the participation. Moreover, considering the risk of expulsion from the group due to inappropriate post, no one shared a disturbing post."

The third opinion based question was about how frequently they contributed/participated to the Facebook group of this course. The options were longed from "nearly I did nothing" to "used it a lot". The mean score was calculated as 3.62 with a standard deviation of 1.18. The frequency distribution of each level of the question was shown in Table 6.

In subsequent to marking their level, the students were asked to state their main reasons for their grade. Eighty seven percent of the students $(n=207)$ filled the box of this question. The results of this open-ended question was listed in Table 7. It reveals that the students mostly visited Facebook group to access lecture notes. One female student reported that "I got almost all shared codes via Facebook. I looked at the codes directly on Facebook in case I couldn't catch up with the course".

Moreover, very few students reported that Facebook group was helping them to follow the lecture during the course or whenever they were absent. Another point was about sharing where the students were pointing that they either shared their own solutions to problems or checked the other students' sharing on the problems. Interestingly enough, one student expressed that "I didn't share anything, but I followed shared notes and photos to archive them. I was actually a secret user."

\section{Facebook in Education Perception Questions}

In the last part of the survey, thirty two 'Facebook in education perception' related 5-Likert scale (from strongly disagree to strongly agree) questions were given to the students. Table 8 shows the items, their mean scores and standard deviations. From the mean scores, it appears that students agree

Table 6. The frequencies for question 3

\begin{tabular}{|l|c|c|l|c|c|}
\hline \multicolumn{1}{|c|}{ Levels } & n & $\%$ & \multicolumn{1}{c|}{ Levels } & n & \% \\
\hline Nearly nothing I did & 13 & 5.4 & Used it & 115 & 47.9 \\
\hline Used very few & 45 & 18.8 & Used it a lot & 52 & 21.7 \\
\hline Not sure & 15 & 6.3 & Total & 240 & 100.0 \\
\hline
\end{tabular}


Table 7. Qualitative analysis of students' answers

\begin{tabular}{|l|l|l|l|}
\hline \multicolumn{1}{|c|}{ Identified Point } & n & \multicolumn{1}{c|}{ Identified Point } & n \\
\hline Lecture notes & 71 & Absence & 10 \\
\hline Nothing shared & 22 & Repeat previous weeks & 7 \\
\hline Notifications & 17 & Ask questions & 6 \\
\hline Follow lecture & 14 & Communication with course instructor & 3 \\
\hline Learning solutions & 13 & Become more social & 3 \\
\hline Studying for exams & 12 & Study better & 3 \\
\hline Shared photos & 11 & Not effective since my phone is old & 2 \\
\hline Shared my solutions & 11 & Increased my participation & 1 \\
\hline
\end{tabular}

with the idea of keeping Facebook course group as secret $(M=4.12)$ and the established group rules $(\mathrm{M}=4.15)$. The students were also noted that using the Facebook course group was not a waste of time $(M=1.63)$ or uninteresting $(M=1.65)$ for them.

Additionally the students disagreed that it was unnecessary to establish rules to use the Facebook group of the course $(M=1.85)$. For instance; even though the students were not sure about the necessity of using a proper Turkish on their Facebook group posts $(\mathrm{M}=2.50)$, they were not perceiving the slangs on the Facebook group as normal $(M=1.67)$. Therefore, possible language related rules could be established as a part of Facebook group rules. Furthermore, the students were in agreement with the punishment of expelling a group member because of a Facebook group rule violation $(\mathrm{M}=3.95)$.

Considering the posts, the students liked very much the idea of sharing photos of board with problem solutions $(\mathrm{M}=4.42)$ by highlighting that these photos influenced their course performance positively $(\mathrm{M}=4.16)$. The students moderately disagreed that all kinds of posts could be shared on the Facebook group of the course $(M=2.95)$. For example; the students were asked whether sharing sexuality, religion or politics related materials on Facebook in general or Facebook course group in specific is normal. For the sexuality related materials, the mean scores slightly changed from 1.60 (on Facebook group of the course) to 1.87 (on Facebook), which demonstrated that the participants disagreed on sharing any post related to sexuality in general or in a group. Similar disagreement was observed on religious posts as well. The students disagreed that religious posts could be submitted to Facebook course group $(M=2.01)$ or to Facebook in general $(M=2.75)$. Nonetheless, the biggest change was observed on the political posts. Although the students still showed disagreement with posting political materials, the mean score increased from 1.71 (for Facebook course group) to 2.57 (Facebook). In general, the students are more sensitive about posting sexuality, religiosity or politics related posts on Facebook course group.

Furthermore, the students noted that they were not afraid of reactions from their classmates $(\mathrm{M}=2.00)$ or their course instructor $(\mathrm{M}=2.34)$ when they posted something on Facebook group. In another question, the students disagreed that they had the fear of having problems between them and their course instructor due to their Facebook group posts $(M=2.32)$. The students also disagreed that there were inappropriate posts on Facebook course group during the semester $(M=1.68)$. Although there was no post sharing moderation process in the Facebook course group or no obvious inappropriate posts, the students agreed that it would be better for a group administrator to check every post prior to their posting on the group wall $(\mathrm{M}=3.58)$.

When the students were asked whether Facebook could be a good learning or teaching tool with a time comparison between the beginning and the end of the course, mean scores do not show much change. For example, the mean score of Facebook as learning tool shifted from 3.72 (at the beginning) to 3.97 (at the end). Similarly, the mean score of Facebook as a teaching tool changed from 3.69 (at 
the beginning) to 3.97 (at the end). Additionally, the students slightly agreed on the ideas of getting extra grades from Facebook course group contributions $(M=3.72)$ and being positively affected by course group toward course interest $(M=3.62)$.

In another dimension, the students disagreed that this Facebook group implementation in a computing course was an intrusion for their private lives $(M=1.91)$. Moreover, the students did not feel any pressure toward 'liking' course instructor's posts on the group $(M=1.54)$. Nevertheless, the students were not decided about fairness of asking students to open a Facebook account only for this implementation $(M=2.46)$. Yet, after joining the Facebook group, the students felt free to use it in a classroom $(\mathrm{M}=3.62)$.

\section{Comparison Tests}

At last but not the least, the survey items were analyzed with comparison based statistical analyses. The initial comparison test was conducted on gender variables with respect to three opinion based Likert questions plus thirty two survey items. The independent sample t-tests revealed only two survey items differentiating with respect to gender variable (Table 9). Male students tended to believe more in the idea that using Facebook in the lectures will not obstruct the free Facebook use. Furthermore, male students liked more the idea of getting extra grades based on their active contribution to course Facebook group. However, the number of members represented in each gender group is not equal; female is 50 and male is 190. That difference might be another reason of having these two statistically differentiated items for this study. Hence, the results should be interpreted accordingly.

Second independent sample t-tests were conducted on school year variable (sophomore versus junior) for three opinion based Likert questions plus thirty two survey items. There was only one item statistically significant for differentiation; item one (Table 10). The result demonstrated that sophomore students appreciated course Facebook group secret feature more than juniors. It might be interpreted as in being relatively newer at the university (not knowing their classmates much) in comparison to juniors

The last comparison test was one-way ANOVA tests based on department variable (civil engineering, industrial engineering versus mechatronic engineering) for three opinion based Likert questions plus thirty two survey items. Totally five items were significantly differentiated around department variable; one opinion based question and four survey items (Table 11). In order to understand which department(s) make difference(s) among others, post-hoc tests were performed. Based on Levene's equality of variance tests, Dunnett C was selected as most appropriate post-hoc test for the items (Table 11).

From the opinion question, it seems that mechatronic engineering students supported the idea of using Facebook group in this computing course more than industrial engineering students. Additionally from the items two, four and five, it reveals that industrial engineering students were not comfortable enough with the idea of Facebook group, in comparison to mechatronic engineering students. It might be the belief that computer programming is much more directly related to mechatronic engineering, but not to industrial engineering. Furthermore, the interest in having a Facebook course group for civil engineering students was lower than mechatronic engineering students. 
Table 8. Survey items with their basic statistics

\begin{tabular}{|c|c|c|}
\hline Item & M & S.D. \\
\hline 1. I liked that the Facebook group was secret. & 4.12 & 0.95 \\
\hline 2. While I was sharing something in the Facebook group, I was afraid of the reaction of other members. & 2.00 & 1.07 \\
\hline 3. While sharing something in the Facebook group, I was afraid of the reaction of the course instructor. & 2.34 & 1.17 \\
\hline 4. Using the Facebook group was a waste of time. & 1.63 & 1.01 \\
\hline 5. The course's Facebook group did not interest me. & 1.65 & 1.00 \\
\hline 6. I think some posts in the Facebook group were inappropriate. & 1.68 & 0.99 \\
\hline 7. I felt that I had to "like" the sharing of course instructor in the Facebook group. & 1.54 & 0.82 \\
\hline 8. At the beginning of the lesson, I thought that Facebook could be a good learning tool. & 3.72 & 1.10 \\
\hline 9. At the beginning of the lesson, I thought that Facebook could be a good teaching tool. & 3.69 & 1.09 \\
\hline 10. At the end of the semester, I thought that Facebook could be a good learning tool. & 3.97 & 1.01 \\
\hline 11. At the end of the semester, I thought Facebook could be a good teaching tool. & 3.97 & 1.00 \\
\hline 12. I believe that students can still be free on Facebook while using Facebook in classroom. & 3.62 & 1.05 \\
\hline 13. Using Facebook in class is an intervention in my private life. & 1.91 & 0.91 \\
\hline $\begin{array}{l}\text { 14. I'm afraid that what I share in the Facebook group will create problems between me and the course } \\
\text { instructor. }\end{array}$ & 2.32 & 1.14 \\
\hline 15. The use of Facebook in the lesson positively affected my interest in the class. & 3.62 & 1.04 \\
\hline 16. All kinds of sharing should be possible within the Facebook group of the course. & 2.51 & 1.20 \\
\hline 17. It is unnecessary to set rules to use the Facebook group of the course. & 1.85 & 1.05 \\
\hline 18. I agree with the rules of the Facebook group of the course. & 4.15 & 0.89 \\
\hline $\begin{array}{l}\text { 19. It is fair to be expelled from the group as a result of violations of the rules of the Facebook group of } \\
\text { the course. }\end{array}$ & 3.95 & 1.08 \\
\hline $\begin{array}{l}\text { 20. It is better an administrator checks the posts before they are shared with the students on the Facebook } \\
\text { group. }\end{array}$ & 3.58 & 1.16 \\
\hline 21. I liked the idea of getting extra points from the level of participation in the Facebook group. & 3.72 & 1.27 \\
\hline 22. It is not fair to just have to open Facebook for the course. & 2.46 & 1.20 \\
\hline 23. It is normal to share things with sexuality within the Facebook group of the course. & 1.60 & 0.95 \\
\hline 24. It is normal to share things with religious elements within the Facebook group of the course. & 2.01 & 1.15 \\
\hline 25. It is normal to share things with political elements within the Facebook group of the course. & 1.71 & 0.94 \\
\hline 26. It is normal to use slang in the Facebook group of the course. & 1.67 & 0.91 \\
\hline 27. I shouldn't have to use Turkish properly in the Facebook group of the course. & 2.50 & 1.18 \\
\hline 28. In general, it is normal to share sexuality in Facebook. & 1.87 & 1.04 \\
\hline 29. In general, it is normal to share things that contain religious elements in Facebook. & 2.75 & 1.22 \\
\hline 30. In general, it is normal to share things with political elements in Facebook. & 2.57 & 1.21 \\
\hline 31. It is a good idea to share photos of the Facebook group on the board. & 4.42 & 0.79 \\
\hline $\begin{array}{l}\text { 32. Students sharing the photos of the board within the course Facebook group affected the my course } \\
\text { performance positively. }\end{array}$ & 4.16 & 1.02 \\
\hline
\end{tabular}


Table 9. The independent sample t-tests results for gender variable

\begin{tabular}{|c|c|c|c|c|c|c|}
\hline Item Number & Gender & $\mathbf{n}$ & $\mathbf{M}$ & SD & $t$ & $p$ \\
\hline \multirow{2}{*}{12} & Female & 50 & 3.24 & 1.00 & \multirow{2}{*}{-2.888} & \multirow{2}{*}{0.004} \\
\hline & Male & 190 & 3.72 & 1.05 & & \\
\hline \multirow{2}{*}{21} & Female & 50 & 3.32 & 1.26 & \multirow{2}{*}{-2.512} & \multirow{2}{*}{0.013} \\
\hline & Male & 190 & 3.82 & 1.26 & & \\
\hline
\end{tabular}

Table 10. The independent sample t-tests results for school year variable

\begin{tabular}{|c|l|c|c|c|c|c|}
\hline \multirow{2}{*}{ Item Number and Content } & \multicolumn{1}{|c|}{ Year } & $\mathbf{n}$ & $\mathbf{M}$ & SD & $t$ & $p$ \\
\hline \multirow{2}{*}{1} & Sophomore & 116 & 4.25 & 0.80 & \multirow{2}{*}{2.142} & \multirow{2}{*}{0.033} \\
\cline { 2 - 6 } & Junior & 124 & 3.99 & 1.06 & & \\
\hline
\end{tabular}

Table 11. The one-way ANOVA and post-hoc tests results for department variable

\begin{tabular}{|c|c|c|c|c|c|c|c|}
\hline Item Number and Content & Levels & $n$ & $M$ & $S D$ & $F$ & $p$ & $\begin{array}{l}\text { Dunnett } C \text { post- } \\
\text { hoc test results }\end{array}$ \\
\hline \multirow{3}{*}{ Opinion Question 1} & Civil Eng. & 71 & 4.34 & 0.84 & \multirow{3}{*}{$\begin{array}{c}3.908 \\
(\mathrm{df}=239)\end{array}$} & \multirow{3}{*}{0.021} & \multirow{3}{*}{ Mech. > Ind. } \\
\hline & Industrial Eng. & 95 & 4.13 & 0.83 & & & \\
\hline & Mechatronic Eng. & 74 & 4.45 & 0.55 & & & \\
\hline \multirow{3}{*}{2} & Civil Eng. & 71 & 1.85 & 1.08 & \multirow{3}{*}{$\begin{array}{c}3.890 \\
(\mathrm{df}=239)\end{array}$} & \multirow{3}{*}{0.022} & \multirow{3}{*}{ Ind. $>$ Mech. } \\
\hline & Industrial Eng. & 95 & 2.23 & 1.14 & & & \\
\hline & Mechatronic Eng. & 74 & 1.84 & 0.92 & & & \\
\hline \multirow{3}{*}{4} & Civil Eng. & 71 & 1.70 & 1.24 & \multirow{3}{*}{$\begin{array}{c}3.862 \\
(\mathrm{df}=239)\end{array}$} & \multirow{3}{*}{0.022} & \multirow{3}{*}{ Ind. $>$ Mech. } \\
\hline & Industrial Eng. & 95 & 1.78 & 1.06 & & & \\
\hline & Mechatronic Eng. & 74 & 1.37 & 0.56 & & & \\
\hline \multirow{3}{*}{5} & Civil Eng. & 71 & 1.73 & 1.12 & \multirow{3}{*}{$\begin{array}{c}5.065 \\
(\mathrm{df}=239)\end{array}$} & \multirow{3}{*}{0.007} & \multirow{3}{*}{$\begin{array}{l}\text { Civil > Mech. } \\
\text { Ind. > Mech. }\end{array}$} \\
\hline & Industrial Eng. & 95 & 1.82 & 1.15 & & & \\
\hline & Mechatronic Eng. & 74 & 1.35 & 0.51 & & & \\
\hline \multirow{3}{*}{22} & Civil Eng. & 71 & 2.10 & 1.08 & \multirow{3}{*}{$\begin{array}{c}4.685 \\
(\mathrm{df}=239)\end{array}$} & \multirow{3}{*}{0.010} & \multirow{3}{*}{$\begin{array}{c}\text { Ind. > Civil } \\
\text { Mech. > Civil }\end{array}$} \\
\hline & Industrial Eng. & 95 & 2.60 & 1.15 & & & \\
\hline & Mechatronic Eng. & 74 & 2.62 & 1.30 & & & \\
\hline
\end{tabular}

\section{DISCUSSION AND CONCLUSION}

Through this study, it was evident that students viewed Facebook as a useful educational tool for a $\mathrm{C}$ programming language course. Two most popular reasons why students liked using Facebook were easy access to lecture notes and prompt notifications of course announcement. Other reasons included easy communication with the course instructor and easy cooperation among friends. These findings correlate with previous literature where students' opinions were in favor of Facebook with 
similar reasons (Cortijo \& Javed, 2014; Özyurt \& Özyurt, 2016). It was interesting to note that students criticized the university learning management system for a lack of active notifications and liked Facebook for the opposite reason. This implies Facebook's potential to replace or support the existing course LMS and also indicates what functions of learning management system must be prioritized in order to meet students' learning needs.

As mentioned earlier, one of the drawbacks of using Facebook for academic purpose was students' reluctance in using a social medium as an educational tool or the blurring of the boundary between education and socialization (Gettman \& Cortijo, 2015). However, such reluctance was not observed among our participants. In this study, participating students generally felt free and no pressure in sharing information on Facebook. One possible explanation can be that the course instructor used the university email to create the course Facebook group making the group look professional and separating academic and personal usage of Facebook. If students were pushed to use their personal accounts to join the course Facebook group, the outcomes of this study would be quite different to what we have obtained. This explanation is also consistent with the fact that students liked their course Facebook group set to "closed" making it more exclusive. Thus, operating the course Facebook group separately and exclusively from the personal Facebook usage will reduce the possible pressure from the students which should be noted for future implementations.

In this study, students seemed to agree with the necessity of the course Facebook group rules and regulations. Students also recognized the need for language related rules and supervision of each post by the group administrator. In particular, students were more sensitive and strict with posts related to sexuality, religion, and politics. This could be due to the nature of the academic discipline. The Facebook group was created in a computer programming course where an intensive exchange of information takes place. As evident in students' response, the course Facebook group was mainly used for accessing lecture notes and uploading lecture related materials. Thus, there was a need for rules and regulations to manage the flow of information and keep up the good quality of each post as requested by the students. As Facebook can sometimes create distractions from learning (Niu, 2019), what students are requesting seems reasonable and appropriate.

Last of all, there were three variables investigated for comparative analysis in this study; gender, school year, and department of each participating student. It seems that male students are more active towards Facebook usage in class and getting extra points for Facebook group participation. It could mean that male students are more active participants for the course Facebook group and thus request appropriate rewards or benefits. However, more female students are required for more comprehensive interpretation of the results.

When students were compared based on the school year level, sophomore students more appreciated their course Facebook group to be secret than junior students did. It signifies different levels of acceptance for the course Facebook group in relation to students' privacy. As sophomore students spent less time in their designated department, there could be a stronger tendency to detach themselves from the school related activities. It is expected that the difference between freshman and senior students would be greater. From this finding, it should be noted that the Facebook group privacy level should be adjusted accordingly based on the school year level.

From the department variable, it seems that mechanical engineering students were the most supportive group for Facebook usage in class. On the other hand, industrial engineering students were less interested in Facebook usage, hesitant to open Facebook account for the course, and afraid of reactions from other students on Facebook. This could be due to different levels of perception for importance of the programming course within their department structure and thus students exhibited different attitude towards Facebook usage. As the programming course is essential in mechanical engineering, it could trigger students' motivation to learn through various educational tools which led to active participation in the Facebook group. This implies that students' perception of Facebook usage can be influenced by their departments. 
The possible implications for prospective practitioners from study can be listed as; (i) Facebook groups hold potentials as an alternative instructional context for computing education, (ii) Facebook group should be set up to 'closed' option and must have clear utilization rules including explicit rewards and punishments, (iii) Facebook groups should set up based on a special email address than course instructor's personal account. (iv) the course instructor should be available online to address any issue or communication request, (v) the students must be free for posting anything to Facebook group while considering the established rules beforehand, and (vi) the students must be free to use Facebook group during the lectures.

\section{Limitations and Further Studies}

Our study reported a number of significant findings on students' perceptions of Facebook groups for educational usage and variables such as gender, school year, and department that can influence students' perceptions. However, these findings were obtained from a specific group of students due to the nature of a case study and further studies are required to elucidate the effectiveness of Facebook (and/or Facebook group) usage in computing education. First of all, our study should be replicated with students from different cultural and ethnic backgrounds. As cultural influences on students' perceptions can possibly induce different outcomes for Facebook usage, more case studies with cultural diversity will complement the results obtained in our study. Second of all, equal distribution of male and female participants within each department will produce more comprehensive results. In addition, freshman and senior students can be included for more specific comparative analysis based on the school year level.

Moreover, a pre-post design study would measure the change for the students. Since the importance of computing education has been increasing dramatically for all disciplines, different departments (especially non-tech programs) should be given similar interventions to have deeper understanding on the effects of social media (or Facebook in specific). The interviews could be integrated to these kind of studies to yield better and deeper comprehension of the topic. Last of all, different courses in computing education can be tested to clarify its influence on students' acceptance of Facebook usage.

As evident in previous literature and current study, Facebook holds a great potential for educational usage. Although this study shows a number of key findings to consider, both educators and learners need to work together and continuously modify the learning environment so that it becomes most effective and ideal for Facebook implementation.

\section{ACKNOWLEDGEMENT}

This research was funded by Woosong University Academic Research in 2021. 


\section{REFERENCES}

Arteaga Sánchez, R., Cortijo, V., \& Javed, U. (2014). Students' perceptions of Facebook for academic purposes. Computers \& Education, 70, 138-149. doi:10.1016/j.compedu.2013.08.012

Aşkar, P., \& Davenport, D. (2009). An investigation of factors related to self-efðcacy for java programming among engineering students. The Turkish Online Journal of Educational Technology, 8(1), 3.

Bolger, F., \& Wright, G. (1992). Reliability and validity in expert judgment. In Expertise and Decision Support. Springer. doi:10.1007/978-0-585-34290-0_4

Dzvapatsva, G. P., Mitrovic, Z., \& Dietrich, A. D. (2014). Use of social media platforms for improving academic performance at further education and training colleges. South African Journal of Information Management, 16(1), 1-7. doi:10.4102/sajim.v16i1.604

Fraenkel, J. R., Wallen, N. E., \& Hyun, H. H. (2012). How to design and evaluate research in education. McGraw-Hill Humanities/Social Sciences/Languages.

Garcia, D., Kassa, Y. M., Cuevas, A., Cebrian, M., Moro, E., Rahwan, I., \& Cuevas, R. (2018). Analyzing gender inequality through large-scale Facebook advertising data. Proceedings of the National Academy of Sciences of the United States of America, 115(27), 6958-6963. doi:10.1073/pnas.1717781115 PMID:29921703

Gettman, H. J., \& Cortijo, V. (2015). “Leave me and my Facebook alone!” Understanding college students' relationship with Facebook and its use for academic purposes. International Journal for the Scholarship of Teaching and Learning, 9(1), 8. doi:10.20429/ijsotl.2015.090108

Jung, E. H. (2018). Age differences in using Facebook: Younger adults vs. older adults. Proceedings of the 30th Australian Conference on Computer-Human Interaction. doi:10.1145/3292147.3292227

Kalin, J. (2012). Doing what comes naturally? Students perceptions and use of collaborative technologies. International Journal for the Scholarship of Teaching and Learning, 6(1), 1-21. https://doi.org/10.20429/ ijsotl.2012.060110

LaRue, E. M. (2012). Using Facebook as course management software: A case study. Teaching and Learning in Nursing, 7(1), 17-22. https://doi.org/10.1016/j.teln.2011.07.004

Lin, P. C., Hou, H. T., Wu, S. Y., \& Chang, K. E. (2014). Exploring college students' cognitive processing patterns during a collaborative problem-solving teaching activity integrating Facebook discussion and simulation tools. The Internet and Higher Education, 22, 51-56. https://doi.org/10.1016/j.iheduc.2014.05.001

Meishar-Tal, H., Kurtz, G., \& Pieterse, E. (2012). Facebook groups as LMS: A case study. International Review of Research in Open and Distance Learning, 13(4), 33-48. https://doi.org/10.19173/irrodl.v13i4.1294

Niu, L. (2019). Using Facebook for academic purposes: Current literature and directions for future research. Journal of Educational Computing Research, 56(8), 1384-1406. https://doi.org/10.1177/0735633117745161

Öztürk, M., \& Akgün, Ö. (2012). University students' purposes in using social networking sites, and their opinions on using these sites in education. Sakarya University Journal of Education, 2(3), 49-67.

Özyurt, Ö., \& Özyurt, H. (2016). Using Facebook to enhance learning experiences of students in computer programming at introduction to programming and algorithm course. Computer Applications in Engineering Education, 24(4), 546-554. https://doi.org/10.1002/cae.21730

Pillay, N., \& Jugoo, V. R. (2005). An investigation into student characteristics affecting novice programming performance. ACM SIGCSE Bulletin, 37, 107-110. 10.1145/1113847.1113888

Sabaitytė, J., \& Davidavičius, S. (2017). Challenges and solutions of adopting public electronic services for the needs of $Z$ generation. International Journal of Learning and Change, 9(1), 17-28. https://doi.org/10.1504/ IJLC.2017.084242 


\section{APPENDIX A - FACEBOOK GROUP RULES FOR THE COURSE}

Dear students, you can read our Facebook group rules below. If there is a vague point, please do not hesitate to communicate with course instructor.

$\S$ You do not have to add the course group's Facebook account to your personal account. This Facebook account is an account that the course instructor opens only for the course, which means not his personal account. Do not send an invitation to his personal account, it will not be accepted.

$\S$ You can share your posts in the Facebook group news feed so that they can be viewed collectively, if your posts concern everyone.

$\S$ You may be expelled from the Facebook group, if your texts or images include discrimination, racism, humiliation, profanity or slang in your posts. Remember to respect human rights and common sense.

$\S$ The limit on your file sharing within the Facebook group is $25 \mathrm{MB}$. You can share files over this size by uploading them into your Dropbox account. Do not use Google Drive or WebTransfer that school does not provide an access.

$\S$ There is no administrator consent process which means you can share your posts without waiting for any approval.

$\S$ You are free to share photos of blackboard taken during the lecture or any other student's course related notes on the Facebook group.

$\S$ You will receive extra points based on your activity level in the Facebook group. Liking every post does not mean that you are active on the Facebook group.

$\S$ The course instructor will share his lecture notes, presentations, assignments and all other announcements on the Facebook group. Therefore, you should join the Facebook group as soon as possible.

$\S$ If you do not have any Facebook account yet, you have two options; (i) you will either open an account for this course, or (ii) you will follow the course from another person's Facebook account (who will not be attending this course) by informing the course instructor.

$\S$ You can follow the course presentations in your Facebook group from your mobile phones during the lecture but you cannot chat with each other. Please, use Facebook's chat feature outside the classroom.. 